\title{
Prognostic Variables of Papillary Thyroid Carcinomas with Local Invasion
}

\author{
Jen-Der LIN, Tzu-Chieh CHAO*, Hsiao-Fen WENG, and Yat-Sen HO** \\ Division of Endocrinology and Metabolism, Department of Internal Medicine, \\ *Department of General Surgery, **Department of Pathology, Chang Gung Memorial Hospital, Taiwan, R.O.C.
}

\begin{abstract}
To evaluate the significance of the extrathyroid extension (ETE) of papillary thyroid carcinoma at the time of diagnosis and the prognostic variables of patients, we retrospectively reviewed 1,013 thyroid cancer patients. Of the 741 papillary thyroid cancer patients, $466(62.9 \%)$ were categorized in clinical stage I and $114(15.4 \%)$ were categorized in clinical stage III. Of the 114 patients in clinical stage III, 81 were female (mean age $44.4 \pm 15.7$ years) and 33 were male (mean age $46.9 \pm 18.1$ years). Of the clinical stage III patients, 104 patients received post-operative radioactive iodide (131I) therapy while 22 patients received external radiotherapy in the neck and upper mediastinum area post-operatively. In the study, age, gender, ${ }^{131}$ I accumulated dose, post-operative serum thyroglobulin (Tg) levels, and survival rate were demonstrated to be statistically significant in the groups with no recurrence and recurrence after treatment. The average follow-up period of these patients was 6.0 years. During this follow-up period, 11 patients expired. Eight died of thyroid cancer $(7.0 \%)$ and 3 died of intercurrent diseases including asthma, renal cell carcinoma and propranolol overdose. Four of the 8 patients $(50 \%)$ died of airway obstruction due to cancer cell invasion. Another 4 died of distant metastases, including 2 patients with skull metastases and brain invasion. The 5- and 10-year survival rates were 0.981 and 0.956 in clinical stage I and 0.923 and 0.843 in clinical stage III, respectively. In conclusion, the survival rate of the ETE of papillary thyroid cancer was lower when compared with stage I, especially in older male patients with higher post-operative serum $\mathrm{Tg}$ levels.
\end{abstract}

Key words: Radioactive iodide, External radiotherapy, Thyroglobulin

(Endocrine Journal 46: 91-98, 1999)

ALTHOUGH well differentiated thyroid carcinoma had been known as a rather indolent malignancy, most studies revealed poor prognosis for papillary thyroid carcinoma with extrathyroid extension (ETE) at the time of operation when they were compared with patients without ETE [1-4]. There is little information, however, about the prognostic variables for papillary thyroid carcinoma with ETE at the time of diagnosis. To evaluate the

Received: December 22, 1997

Accepted: October 16, 1998

Correspondence to: Dr. Jen-Der LIN, Division of Endocrinology and Metabolism, Chang Gung Memorial Hospital, 5 Fu-Shin St., Kweishan County, Taoyuan Hsien, Taiwan, R.O.C. significance of ETE of papillary thyroid carcinoma in terms of survival and tumor recurrence, and to determine the prognostic variables of patients, we retrospectively reviewed and analyzed 1,013 thyroid cancer patients.

\section{Subjects and Methods}

From January, 1977 to December, 1995, 1,013 thyroid carcinoma patients received their treatment and were followed up at the Chang Gung Medical Center in Linkou, Taiwan. Of these patients, 910 cases of papillary or follicular thyroid carcinoma including 741 papillary thyroid carcinoma patients were diagnosed. In this medical center near total 
thyroidectomy or modified radical neck thyroidectomy were conducted on the papillary thyroid cancer patients with local invasion. Whole body ${ }^{131}$ I images were performed 4 to 6 weeks after the operations after using $5 \mathrm{mCi}$ of ${ }^{131} \mathrm{I}$ for diagnostic scans. If ${ }^{131}$ I uptake of the neck was over $1 \%$ of the dose at $24 \mathrm{~h}$, the thyroid remnant was ablated with 30 to $100 \mathrm{mCi}$ of ${ }^{131} \mathrm{I}$. If distant metastatic lesions were detected by the $5 \mathrm{mCi}^{131} \mathrm{I}$ scan, 100 to $150 \mathrm{mCi}^{131} \mathrm{I}$ was used for treatment. Hospitalization for isolation was arranged if the dose of ${ }^{131} \mathrm{I}$ was over $30 \mathrm{mCi}$. Whole body scans were carried out 2 weeks after the higher therapeutic dose (over $30 \mathrm{mCi}$ ) of ${ }^{131} \mathrm{I}$ was given. Long term thyroxine replacements were given after the therapeutic whole body imagings. The patients were asked to follow a low iodine diet beginning at the week before the diagnostic scan until the day after the administration of the ${ }^{131}$ I therapy as previously described [5]. Repeat cancer investigation including chest $\mathrm{x}$-ray, $5 \mathrm{mCi}{ }^{131} \mathrm{I}$ scan and the serum thyroglobulin ( $\mathrm{Tg}$ ) level was performed a half to one year later 4 to 6 weeks after thyroxine replacement was stopped. Treatment was continued until the ${ }^{131}$ I uptake over the neck region was less than $1 \%$ and no distant metastasis was evident. The patients received follow-up after one year, and then 2 years thereafter. If the follow-up scan was negative, then further scans were obtained only at 5-year intervals unless clinical or other laboratory data revealed recurrent thyroid carcinoma.

External radiotherapy to both sides of the neck, from the thyroid to the supraclavicular fossae and extending down to the superior mediastinum, was performed on patients with residual tumor that could not be removed by surgery. Most patients received total tumor doses of $60 \mathrm{~Gy}$ in 30 days. Treatment in 2 Gy fractions to both fields was continued daily for 6 weeks.

In this study, tumor staging was classified according to the clinical staging as described by DeGroot [6]. Stage I is a tumor with one or more intrathyroidal foci. Stage II is a tumor with cervical metastases. Stage III is a thyroid tumor with ETE including fixed cervical metastases. Stage IV is metastatic lesions outside of the neck. All the patients were categorized in groups with no recurrence or recurrence including lymph node metastasis, local recurrence and distant metastasis, at the end of 1995 after the treatment. Hospital records were reviewed and the following data were stored in the computer: age, gender, histopathological type, primary tumor size, method of operation, operative findings, post-operative serum $\mathrm{Tg}$ level, results of the post-operative $5 \mathrm{mCi}$ of ${ }^{131}$ I cancer work ups, accumulation of therapeutic ${ }^{131}$ I doses, and the post-operative chest $\mathrm{x}$-ray findings. The post-operative serum $\mathrm{Tg}$ level was detected with a $\mathrm{Tg}$ kit (CIS bio international, France). The detection limit of the $\mathrm{Tg}$ kit was 0.5 $\mathrm{ng} / \mathrm{mL}$. Interassay coefficient of variation was $8 \%$ at a $\mathrm{Tg}$ level of $4.9 \mathrm{ng} / \mathrm{mL}, 6.9 \%$ at $223.2 \mathrm{ng} / \mathrm{mL}$, and $5.1 \%$ at $312.9 \mathrm{ng} / \mathrm{mL}$.

Data were presented as the mean $\pm S D$, and univariate and multivariate statistical analyses of the significance of the various factors were performed by the Kaplan-Meier method and the log-rank test [7]. Statistical significance was regarded as corresponding to a $P$ value less than or equal to 0.05 . Actuarial survival rates were calculated by the Kaplan-Meier method and differences in survival rates were examined by means of the Breslow and Mantel-Cox tests.

\section{Results}

Of the 741 papillary thyroid carcinoma patients, $466(62.9 \%), 126(17.0 \%), 114(15.4 \%)$, and $35(4.7 \%)$ patients were categorized as clinical stage I, II, III, and IV, respectively, at the time of diagnosis. Table 1 shows the clinical presentations and results of the treatment of stage I and III patients. The patients with papillary thyroid carcinoma with ETE were older, had a higher male ratio, bigger tumor size and higher post-operative serum $\mathrm{Tg}$ level. There were fewer stage III patients who were disease-free and surviving during the follow-up period. These differences between the two groups were statistically significant $(P<0.05)$.

Of the 114 patients in clinical stage III at the time of diagnosis, 81 were female with a mean age of $44.4 \pm 15.7$ years, and 33 were male with a mean age of $46.9 \pm 18.1$ years. The differences in age in both genders were not statistically significant $(P=0.46)$. The invasive cancer tissue of 29 patients (25.4\%) could not be removed completely by a surgical procedure. Eight-five patients (74.6\%) presented with local invasion, which could be resected by a surgical procedure (Table 2). Patients with invasive cancer tissue that could not be 
Table 1. Clinical presentations of papillary thyroid cancer patients in clinical stages I and III

\begin{tabular}{|c|c|c|c|}
\hline \multirow[b]{2}{*}{ Factor } & \multicolumn{3}{|c|}{ Stage at diagnosis } \\
\hline & $\begin{array}{l}\text { Stage I } \\
(n=466)\end{array}$ & $\begin{array}{c}\text { Stage III } \\
(\mathrm{n}=114)\end{array}$ & $P$ value \\
\hline \multicolumn{4}{|l|}{ Age (yrs) } \\
\hline$\leq 45 \mathrm{yrs} />45 \mathrm{yrs}$ & $330 / 136$ & $55 / 59$ & 0.0004 \\
\hline \multicolumn{4}{|l|}{ Gender } \\
\hline $\mathrm{F} / \mathrm{M}$ & $386 / 80$ & $81 / 33$ & 0.0066 \\
\hline \multicolumn{4}{|l|}{ Operative method } \\
\hline Total/Subtotal/Lob* & $352 / 89 / 24$ & $94 / 16 / 3$ & 0.2097 \\
\hline \multicolumn{4}{|l|}{ Tumors size } \\
\hline$\leq 2.5 \mathrm{~cm} />2.5 \mathrm{~cm}$ & $272 / 165$ & $41 / 63$ & 0.0001 \\
\hline \multicolumn{4}{|l|}{ Post-operative ${ }^{131}$ I uptake } \\
\hline \multicolumn{4}{|l|}{ Tg level } \\
\hline \multicolumn{4}{|l|}{${ }^{131}$ I accumulative dose } \\
\hline$\leq 30 \mathrm{mCi} />30 \mathrm{mCi}$ & $119 / 262$ & $34 / 70$ & 0.8692 \\
\hline \multicolumn{4}{|l|}{ Present status } \\
\hline No recurrence/Recurrence & $451 / 15$ & $83 / 31$ & 0.0001 \\
\hline \multicolumn{4}{|l|}{ Survival } \\
\hline $\mathrm{Y} / \mathrm{N}$ & $457 / 9$ & $103 / 11$ & 0.0002 \\
\hline
\end{tabular}

*: Total thyroidectomy/Subtotal thyroidectomy/Lobectomy.

t: including one patient who received biopsy only when in stage III.

Table 2. Clinical presentation of the two groups with different operative findings and surgical results in well differentiated thyroid cancer in clinical stage III at time of diagnosis

\begin{tabular}{|c|c|c|c|}
\hline \multirow[b]{2}{*}{ Factors } & \multicolumn{2}{|c|}{ Surgical findings } & \multirow[b]{2}{*}{$P$ value } \\
\hline & $\begin{array}{l}\text { Complete resection } \\
\qquad(\mathrm{n}=85)\end{array}$ & $\begin{array}{l}\text { Incomplete resection } \\
\qquad(\mathrm{n}=29)\end{array}$ & \\
\hline \multicolumn{4}{|l|}{ Age at diagnosis } \\
\hline$\leq 45 \mathrm{yrs} />45 \mathrm{yrs}$ & $43 / 42$ & $12 / 17$ & 0.5210 \\
\hline \multicolumn{4}{|l|}{ Gender } \\
\hline $\mathrm{F} / \mathrm{M}$ & $67 / 18$ & $14 / 15$ & 0.0038 \\
\hline \multicolumn{4}{|l|}{ Operative method } \\
\hline Lob/Subtot / Tot* & $2 / 10 / 73$ & $1 / 6 / 21$ & 0.4052 \\
\hline \multicolumn{4}{|l|}{ Tumor size } \\
\hline$\leq 2.5 \mathrm{~cm} />2.5 \mathrm{~cm}$ & $32 / 49$ & $9 / 14$ & 0.8343 \\
\hline \multicolumn{4}{|l|}{ Clinical presentation } \\
\hline Neck nodule/Lymph node/Others & $79 / 5 / 1$ & $27 / 1 / 0$ & 0.7526 \\
\hline \multicolumn{4}{|l|}{ Post-operative ${ }^{131}$ I uptake } \\
\hline$\leq 1 \% />1 \%$ & $7 / 40$ & $4 / 13$ & 0.6645 \\
\hline \multicolumn{4}{|l|}{ Post-operative thyroglobulin } \\
\hline $\begin{array}{l}\leq 3 \mathrm{ng} / \mathrm{ml} />3 \mathrm{ng} / \mathrm{ml} \\
{ }^{131} \text { I therapy accumulative dose }(\mathrm{mCi})\end{array}$ & $22 / 54$ & $1 / 23$ & 0.0253 \\
\hline$\leq 30 \mathrm{mCi} />30 \mathrm{mCi}$ & $28 / 50$ & $6 / 20$ & 0.3343 \\
\hline \multicolumn{4}{|l|}{ Present status $^{\#}$} \\
\hline No recurrence / Recurrence & $75 / 10$ & $8 / 21$ & 0.0001 \\
\hline \multicolumn{4}{|l|}{ Survival } \\
\hline Yes/No & $81 / 4$ & $22 / 7$ & 0.0070 \\
\hline
\end{tabular}

*: Lobectomy/Subtotal thyroidectomy/Total thyroidectomy. \#: Status at the end of 1995. 
removed completely had a higher male ratio, higher Tg level, advanced follow up stage, and lower survival rate. One hundred and four out of the 114 patients received post-operative ${ }^{131} \mathrm{I}$ therapy with a mean dose of $135.0 \pm 13.3 \mathrm{mCi}$ (range 30 to $650 \mathrm{mCi}$ ). Of the 104 patients who received ${ }^{131} \mathrm{I}$ therapy, 72 patients were without recurrence at the end of 1995. Otherwise, 10 and 11 patients had local recurrence and distant metastases, respectively, at the end of 1995 . One patient in clinical stage III and 2 in clinical stage IV died of cancer during this period. On the other hand, 2 patients in clinical stage I died due to non-cancer causes. Ninety-three patients had a $\mathrm{Tg}$ level before and after the ${ }^{131} \mathrm{I}$ therapy. In seventy-seven of the $93(82.8 \%)$ patients, the serum $\mathrm{Tg}$ level decreased. The mean $\mathrm{Tg}$ level before and after treatment were $43.2 \pm 12.2$ to $18.8 \pm 7.6 \mathrm{ng} / \mathrm{mL}$. Twenty-two patients received external radiotherapy in the neck and upper mediastinum area postoperatively. Of these patients, one received external radiotherapy over the brain after skull metastases, which were detected during the follow-up period. Table 3 shows the clinical information of these 114 patients in 2 groups, one with improvement, those in no recurrence at the end of 1995, and other recurrence or distant metastases during the follow-up period.
Age, gender, the one month post-operative serum $\mathrm{Tg}$ level, ${ }^{131}$ I accumulated dose, and survival rate of these two groups were significantly different $(P<0.05)$. On the other hand, operative methods, and tumor size in these two groups were not statistically different. Multivariate statistical analysis of the significance of various factors showed that age and gender were independent factors in the prognosis of these patients. Relative risk for patients older than 45 years old and male was 11.5 and 12.1, respectively (Table 4).

The average follow-up period for the patients in our study was 6.0 years. Eleven patients expired during this follow-up period, 8 from thyroid cancer (7.0\%) and 3 from intercurrent diseases: asthma, renal cell carcinoma and propranolol overdose. Fig. 1 shows the Kaplan-Meier survival curve of these patients. The 5-, and 10-year survival rates were 0.981 , and 0.956 in clinical stage I and 0.923 , and 0.843 in clinical stage III, respectively. Of the 8 patients died of papillary thyroid cancer, 5 received external radiotherapy on the neck and upper mediastinum for residual tumor. One received external radiotherapy of the brain 5 years after the operation. Five of these 8 patients received ${ }^{131} \mathrm{I}$ treatment with accumulated doses ranging from $100 \mathrm{mCi}$ to $560 \mathrm{mCi}$. Four patients $(50 \%)$ died of

Table 3. Clinical presentations of papillary thyroid carcinoma with extrathyroid extension in groups with no recurrence and recurrence during the follow-up period

\begin{tabular}{|c|c|c|c|c|c|}
\hline \multirow[b]{2}{*}{ Factor } & \multicolumn{2}{|c|}{ Present status } & \multirow[b]{2}{*}{$P$ value } & \multirow[b]{2}{*}{$\begin{array}{l}\text { Relative } \\
\text { risk }\end{array}$} & \multirow[b]{2}{*}{$\begin{array}{l}95 \% \text { confidence } \\
\text { interval }\end{array}$} \\
\hline & $\begin{array}{l}\text { No recurrence } \\
\quad(n=83)\end{array}$ & $\begin{array}{l}\text { Recurrence } \\
(n=31)\end{array}$ & & & \\
\hline \multicolumn{6}{|l|}{ Age (yrs) } \\
\hline$\leq 45 \mathrm{yrs} />45 \mathrm{yrs}$ & $45 / 38$ & $10 / 21$ & 0.0033 & 2.457 & $1.05-5.73$ \\
\hline \multicolumn{6}{|l|}{ Gender } \\
\hline $\mathrm{F} / \mathrm{M}$ & $68 / 15$ & $13 / 18$ & 0.0001 & 6.277 & $2.65-14.88$ \\
\hline \multicolumn{6}{|l|}{ Operative method } \\
\hline Total/Subtotal/Lob* & $71 / 10 / 2$ & $23 / 6 / 1$ & 0.5317 & - & - \\
\hline \multicolumn{6}{|l|}{ Tumors size $(\mathrm{cm})$} \\
\hline$\leq 2.5 \mathrm{~cm} />2.5 \mathrm{~cm}$ & $34 / 44$ & $7 / 19$ & 0.2025 & 2.097 & $0.80-5.52$ \\
\hline \multicolumn{6}{|l|}{ Post-operative ${ }^{131}$ I uptake } \\
\hline$\leq 1 \% />1 \%$ & $7 / 40$ & $4 / 13$ & 0.6645 & 0.569 & $0.14-2.25$ \\
\hline \multicolumn{6}{|l|}{ Tg level (ng/ml) } \\
\hline$\leq 3(\mathrm{ng} / \mathrm{ml}) />3(\mathrm{ng} / \mathrm{ml})$ & $22 / 54$ & $1 / 23$ & 0.0253 & 9.370 & $1.62-54.03$ \\
\hline \multicolumn{6}{|l|}{${ }^{131}$ I accumulative dose } \\
\hline$\leq 30 \mathrm{mCi} />30 \mathrm{mCi}$ & $30 / 47$ & $4 / 23$ & 0.0391 & 3.670 & $1.21-11.16$ \\
\hline \multicolumn{6}{|l|}{ Survival } \\
\hline $\mathrm{Y} / \mathrm{N}$ & $81 / 2$ & $22 / 9$ & 0.0001 & 16.568 & $4.55-60.28$ \\
\hline
\end{tabular}

*: Total thyroidectomy / Subtotal thyroidectomy / Lobectomy. ${ }^{+}$: including one patient who received biopsy only on recurrence. 
Table 4. Multiple logistic regression model predicting progression to clinical presentations of papillary thyroid carcinoma with extrathyroid extension in no recurrence and recurrence groups during the follow-up period

\begin{tabular}{lccc}
\hline Factor & $P$ value & Relative risk & $\begin{array}{c}95 \% \\
\text { confidence interval }\end{array}$ \\
\hline Age $(\leq 45 \mathrm{yrs} />45 \mathrm{yrs})$ & 0.0133 & 11.5 & $1.66-79.89$ \\
Gender $(\mathrm{M} / \mathrm{F})$ & 0.0052 & 12.1 & $2.10-68.87$ \\
\hline
\end{tabular}

Dependent variable: clinical presentations of papillary thyroid carcinoma with extrathyroid extension in recurrence and no recurrence. Independent variables: age, gender, operative method, tumor size, post-operative ${ }^{131} \mathrm{I}$ uptake, thyroglobulin level.

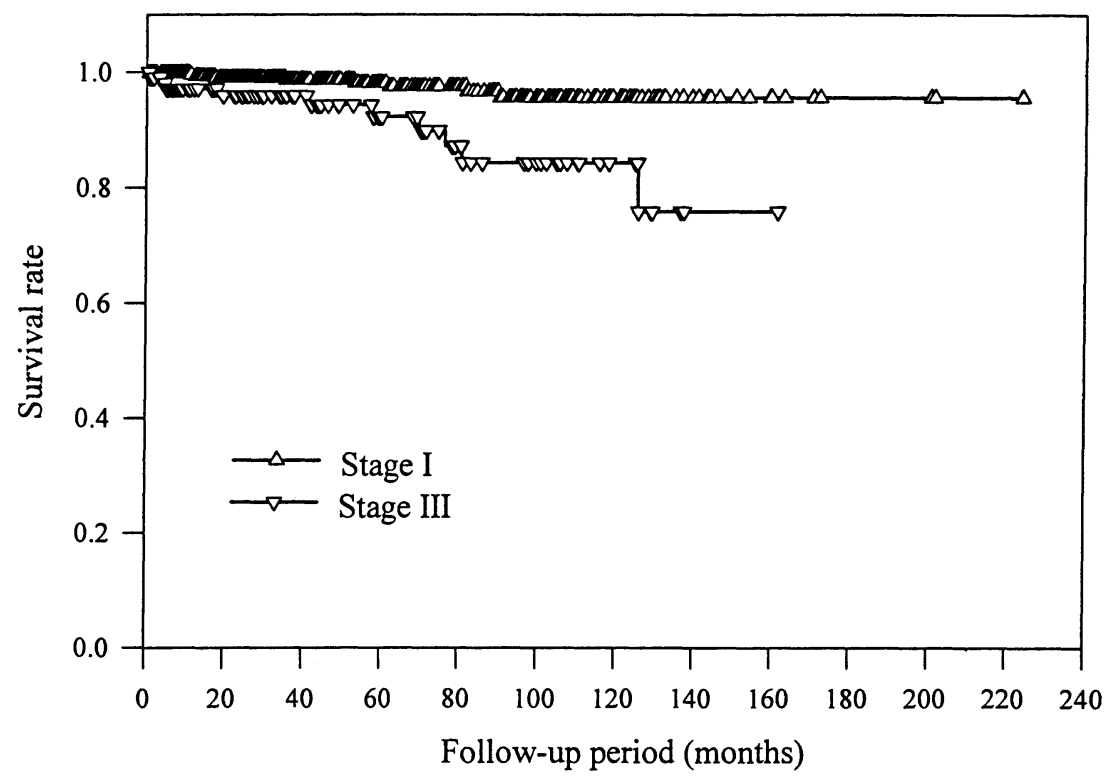

Fig. 1. Kaplan-Meier survival curve of papillary thyroid carcinomas in clinical stage I and III patients.

airway obstruction from cancer cell invasion. Four patients died of distant metastases including 2 skull metastases and brain invasion.

\section{Discussion}

Previous studies have indicated that age, histopathological type, tumor size, post-operative $\mathrm{Tg}$ level, clinical staging, and post-operative $\mathrm{x}$-ray results were the significant prognostic factors for papillary and follicular thyroid carcinomas in this area $[3,8]$. Further investigation with these data was performed to determine the prognostic variable for clinical stage III papillary thyroid carcinoma patients. Papillary thyroid carcinoma had been known to be more common with cervical lymph node metastases than follicular carcinoma $[9,10]$. As our study showed, about half of the mortality in the papillary thyroid cancer patients was due to local tumor invasion [11-13]. Although most of the patients in our study received treatment that included nearly total thyroidectomy with lymph node dissection, post-operative ${ }^{131} \mathrm{I}$ treatment and one-fifth of these patients received external radiotherapy, $7 \%$ of the patients still died of thyroid cancer. The ratio of papillary thyroid cancer with ETE and the mortality rate of patients with ETE in our study was close to that in the series from Mayo Clinic [14] and Mazzaferri et al. [11]. This ratio of 
papillary thyroid cancer with ETE is higher than in the whole series of thyroid carcinoma from Mellière et al. [12].

Female patients dominate well-differentiated thyroid cancer patients. In previous studies, gender was not shown to affect the outcome of treatment in well-differentiated thyroid cancer patients $[1,3$, $4,11]$ but in this study, once ETE of papillary thyroid carcinoma was present at the time of operation, male patients demonstrated a poorer prognosis than females. Our results were in accordance with the large series studies by McConahey et al. [14], Simpson et al. [15], and a long term follow-up study by Schindler et al. [16]. There is a need to further investigate the reasons for the poorer prognosis of male patients. More aggressive surgical procedures for male patients with ETE of papillary thyroid cancer are also advocated. The data from the Memorial SloanKettering Cancer Center on 1,012 differentiated thyroid carcinomas, however, did not show that gender affected survival in patients with ETE [17].

Serum Tg levels have been used as a tumor marker in the follow-up of well-differentiated thyroid cancer patients [18-21]; and it was previously reported that the post-operative serum $\mathrm{Tg}$ level can be used as a prognostic factor in these patients [8]. In a recent study by DeGroot $e t$ al., patients who had a serum Tg level below $2 \mathrm{ng} / \mathrm{mL}$ and underwent thyroid hormone replacement therapy or who had a serum $\mathrm{Tg}$ level below $3 \mathrm{ng} /$ $\mathrm{mL}$ and did not undergo thyroid hormone replacement, rarely experienced tumor recurrence [22]. A high serum Tg level in the poorer prognostic patient group may reveal either residual tumor tissues that were not removed by surgery or distant metastases that could not be detected by ${ }^{131} \mathrm{I}$ or other non-invasive examinations in the study. High one month post-operative serum $\mathrm{Tg}$ levels could be regarded as an ominous sign of papillary thyroid carcinoma with ETE.

In the analysis of 79 differentiated thyroid carcinomas with ETE from the Memorial SloanKettering Cancer Center, Andersen et al. [17] concluded that survival of patients was adversely affected by nonpapillary histology, distant metastasis, age $>45$, tumor size $>4 \mathrm{~cm}$, and incomplete excision. The presence of thyroid carcinoma adherences to the trachea, esophagus or soft tissues were not necessarily associated with poor prognosis $[12,23]$. Although an aggressive surgical procedure including total resection was advocated for thyroid carcinoma with trachea or esophagus invasion [12], whether the resection should be performed with acceptable morbidity of the papillary thyroid carcinoma needs further investigation. The data from the Mayo Clinic series of 48 patients with well differentiated thyroid cancer invading the upper aerodigestive tract showed that an aggressive radical surgical procedure did not improve the survival of the patients [24]. In the current study, most of our patients received conservative surgical treatment; if the trachea or esophagus invasion could be completely eliminated, the patient received postoperative ${ }^{131}$ I treatment and external radiotherapy. During this limited follow-up study, the 5- and 10year survival rates were comparable with those in previous studies [24].

The role of adjuvant external radiotherapy for the post-operative treatment of well differentiated human thyroid cancer is still a controversial issue $[25,26]$, although its use has been reported in patients with well-differentiated thyroid cancer with post-operative residual disease, local recurrence, or in ${ }^{131} \mathrm{I}$ treatment refractory patients $[27,28]$. In a recent study with a limited followup, Lin et al. [29] found that external radiotherapy did not improve the survival of patients with welldifferentiated thyroid cancer at an advanced clinical stage. Although survival was not improved, the reduction of residual tumor size and improvement in the quality of life were expected in the patients who received external radiotherapy. To enhance the effect of external radiotherapy, a combination of doxorubicin and radiation therapy was advocated for local advanced thyroid carcinomas [30]. The median survival time was 4 years with better quality of life obtained for the well differentiated papillary, follicular or mixed type tumor.

In conclusion, papillary carcinoma patients with ETE seemed to have a poor prognosis when they were compared with intrathyroid papillary carcinoma patients, especially older patients, male patients and those with a higher post-operative serum Tg level. 


\section{References}

1. Tubiana $M$, Schlumberger $M$, Rougier $P$, Laplanche A, Benhamou E, Gardet P, Caillou B, Travagli JP, Parmentier C (1985) Long term results and prognostic factors in patients with differentiated thyroid carcinoma. Cancer 55: 794-804.

2. Cady B, Sedgwick C, Meissner W, Wool MS, Salzman FA, Werber J (1979) Risk factor analysis in differentiated thyroid cancer. Cancer 43: 810-820.

3. Lin JD, Huang MJ, Huang BY, Huang HS, Jeng LB (1994) Thyroid cancer treated in Chang Gung Memorial Hospital (Northern Taiwan), during the period: 1979-1992: Clinical presentation, pathological finding, analysis of prognostic variables and results of treatment. J Surg Oncol 57: 244-255.

4. DeGroot LJ, Kaplan EL, McCormick M, Straus FH (1990) Nature history, treatment, and course of papillary thyroid carcinoma. J Clin Endocrinol Metab 71: 414-424.

5. Maxon HR, Thomas SR, Boehringer A, Drilling J, Sperling MI, Sparks JC, Chen IW (1983) Low iodine diet and I 131 ablation of thyroid remnants. Clin Nucl Med 8: 123-126.

6. DeGroot LJ (1995) Thyroid neoplasia. In: DeGroot LJ (eds) Endocrinology. W.B. Saunders Press, Philadelphia, 834-854.

7. Cox DR (1972) Regression models and life tables. I $R$ Stat Soc 34: 197-219.

8. Lin JD, Jeng LB, Chao TC, Weng HF, Huang HS (1996) Surgical treatment of papillary and follicular thyroid carcinoma. Int Surg 81: 61-66.

9. Sellers M, Beenken S, Blankenship A, Soong SJ, Turbat-Herrera E, Urist M, Maddox W (1992) Prognostic significance of cervical lymph node metastases in differentiated thyroid cancer. Am J Surg 164: 578-581.

10. Coburn MC, Wanebo HJ (1992) Prognostic factors and management consideration in patients with cervical metastases of thyroid cancer. Am J Surg 164: 671-676.

11. Mazzaferri EL, Young RL (1981) Papillary thyroid carcinoma: A 10 year follow-up report of the impact of therapy in 576 patients. Am J Med 70: 511-518.

12. Melliére DJM, Yahia NEB, Becquemin JP, Lange $F$, Boulahdour H (1993) Thyroid carcinoma with tracheal or esophageal involvement: Limited or maximal surgery? Surgery 113: 166-172.

13. Tollefsen HR, DeCosse JJ, Hutter RVP (1964) Papillary carcinoma of the thyroid. A clinical and pathological study of 70 fatal cases. Cancer 17: 10351044.

14. McConahey WM, Hay ID, Woolner LB, van
Heerden JA, Taylor WF (1986) Papillary thyroid cancer treated at the Mayo Clinic, 1946 through 1970: Initial manifestations, pathologic findings, therapy, and outcome. Mayo Clin Proc 61: 978-996.

15. Simpson WJ, McKinney SE, Carruthers JS, Gospodarowicz MK, Sutcliffe SB, Panzarella T (1987) Papillary and follicular thyroid cancer prognostic factors in 1,578 patients. Am J Med 83: 479-488.

16. Schindler AM, van Melle G, Evequoz B, Scazziga B (1991) Prognostic factors in papillary carcinoma of the thyroid. Cancer 68: 324-330.

17. Andersen PE, Kinsella J, Loree TR, Shaha AR, Shah JP (1995) Differentiated carcinoma of the thyroid with extrathyroidal extension. Am J Surg 170: 467470.

18. Mueller-Gaertner HW, Brzac HT, Rehpenning W (1991) Prognostic indices for tumor relapse and tumor mortality in follicular thyroid carcinoma. Cancer 67: 1903-1911.

19. Ashcraft MW, van Herle AJ (1981) The comparative value of serum thyroglobulin measurements and iodine 131 total body scans in the follow-up study of patients with treated differentiated thyroid cancer. Am J Med 71: 806-814.

20. van Herle AJ, Rosenblit PD, van Herle TL, van Herle P, Greipel M, Kellett K (1989) Immunoreactive thyroglobulin in sera and saliva of patients with various thyroid disorders: Role of autoantibodies. $J$ Endocrinol Invest 12: 177-182.

21. Harvey RD, Matheson NA, Grabowski PS, Rodger $A B$ (1990) Measurement of serum thyroglobulin is of value in detecting tumor recurrence following treatment of differentiated thyroid carcinoma by lobectomy. Br J Surg 77: 324-326.

22. Ozata M, Suzuki S, Miyamoto T, Liu RT, FierroRenoy F, DeGroot LJ (1994) Serum thyroglobulin in the follow-up of patients with treated differentiated thyroid cancer. J Clin Endocrinol Metab 79: 98-105.

23. Tovi F, Goldstein J (1985) Locally aggressive differentiated thyroid carcinoma. J Surg Oncol 29: 99-104.

24. Lipton RJ, McCaffrey TV, van Heerden JA (1987) Surgical treatment of invasion of the upper aerodigestive tract by well differentiated thyroid carcinoma. Am J Surg 154: 363-367.

25. Benker G, Olbricht TH, Reinwein D, Reiners C, Sauerwein W, Krause U, Mlynek ML, Hirche H (1990) Survival rates in patients with differentiated thyroid carcinoma. Influence of postoperative external radiotherapy. Cancer 65: 1517-1520. 
26. Dinneen SF, Valimaki MJ, Bergstralh EJ, Goellner JR, Gorman CA, Hay ID (1995) Distant metastases in papillary thyroid carcinoma: 100 cases observed at one institution during 5 decades. J Clin Endocrinol Metab 80: 2041-2045.

27. Chung CT, Sagerman RH, Ryoo MC, King GA, Yu WS, Dalal PS, Emmanuel IG (1980) External irradiation for malignant thyroid tumors. Radiology 136: 753-756.

28. Tubiana $M$ (1981) External radiotherapy and radioiodine in the treatment of thyroid cancer. World J Surg 5: 75-84.

29. Lin JD, Tsang NM, Huang MJ, Weng HF (1997) The results of external beam radiotherapy in the patients with well differentiated thyroid carcinoma. Jpn J Clin Oncol 27: 244-247.

30. Kim JH, Leeper RD (1987) Treatment of locally advanced thyroid carcinoma with combination doxorubicin and radiation therapy. Cancer 60: 23722375. 